\title{
Bloodstream infections initiated by ESBL-producing Escherichia coli in neonates and infants at two hospitals in Yaoundé, Cameroon
}

\author{
Carole Suzie Lacmago TITSAMP ${ }^{1}$, Hortense Kamga GONSU ${ }^{2}$ et \\ Simon Ngamli FEWOU ${ }^{*}$ \\ ${ }^{1}$ Department of clinical biochemistry, Faculty of medicine and biomedical sciences, Université des Montagnes, \\ Bangangté, Cameroon. \\ ${ }^{2}$ Department of microbiology, Faculty of medicine and biomedical sciences, University of Yaoundé I, Yaoundé, \\ Cameroon. \\ ${ }^{*}$ Corresponding author; E-mail: simon.fewou@gmail.com
}

\begin{tabular}{ccc}
\hline Received: 18-01-2021 & Accepted: 20-06-2021 & Published: 30-06-2021 \\
\hline
\end{tabular}

\begin{abstract}
Early diagnosis and probabilistic antibiotic therapy based on known bacterial ecology and antibiotic sensibility can reduce mortality and morbidity in pathologies caused by a bacterial infection. This study aimed at determining the prevalence and risk factors of extended-spectrum $\beta$-lactamases (ESBLs)-producing Escherichia coli isolated from blood cultures of neonates and infants population. We conducted a cross-sectional study during which pathogenic bloodstream isolates were identified. Antibiotic susceptibility test was performed on Escherichia coli isolates and phenotypic confirmation of ESBL production by Escherichia coli was performed by a double-disc synergy test. Over the course of this study, 298 blood cultures were performed and $129(43.3 \%)$ positive cultures were obtained. Of the 129 bacterial isolates, 90 (69.7\%) were Escherichia coli and $39(30.2 \%)$ were other bacteria strains that included Klebsiella oxytoca, Streptococcus pneumonia, and Coagulase-negative staphylococci. Antibiotic susceptibility test indicated that Escherichia coli isolates were resistant to cephalosporin, penicillin, sulfonamide, and aminoglycoside antibiotic families. Further analysis indicated that $31(34.4 \%)$ Escherichia coli strains were ESBL producers and risk factors for bloodstream infection by ESBLproducing Escherichia coli were prior to exposure to antibiotics and immune system depression. These findings clearly extend our understanding of the type of resistant initiated by ESBL-producing Escherichia coli in bloodstream infection of neonates, and infants and also provides useful information that can guide the establishment of an efficient therapeutic strategy for the community- and hospital-acquired bloodstream infection.
\end{abstract}

(C) 2021 International Formulae Group. All rights reserved.

Keywords: Bloodstream infection, Escherichia coli, antibiotic resistance, ESBLs, neonates, risk factors.

\section{INTRODUCTION}

The World Health Organization (WHO) has reported approximately 140.87 million newborns in the year 2015 (Roser et al., 2020). Moreover, 2.5 million deaths among newborns within the first four weeks of life were also reported (WHO, 2019). At the current death rate, 30 million newborns will die within the first 28 days of life between 2017 and 2030 (WHO, 2019). The vast majority (30-40\%) of 
these deaths is due to neonatal infections (THE WHO YOUNG INFANTS STUDY GROUP, 2019).

Neonatal and infant infection is a major cause of morbidity and mortality (Paneth and Thompson, 2018). It affects more than $1 \%$ of births and 10 to $15 \%$ of infants admitted to an intensive care unit and there are several chronological stages in neonatal infections (Tam and Bendel, 2017). Throughout intrauterine life, the embryo and the fetus are at risk of being affected by various infectious agents carried by the mother. After birth, newborn babies at term and/or premature babies are very vulnerable to infection (Remington and Klein, 1995). Therefore, rigorous hygiene is essential to avoid the postnatal infection. However, the uncontrolled or misuse of antimicrobial molecules may induce resistance, hence increasing the risk of therapeutic failure. Antimicrobials can effectively fight infections and antibiotic therapy is the most widely used control methods for bacterial infections. Used as a preventive or curative, antibiotic therapy has saved a large number of lives. Nowadays antibiotics are less and less effective due to the appearance of resistant strains.

Escherichia coli (E. coli) is a bacteria species with versatile characteristics which comprise commensal as well as pathogenic variants that cause diseases in human and animals (Leimbach et al., 2013; Daga et al., 2019). In addition, pathogenic E. coli strains express specific proteins that contribute to the emergences of antimicrobial resistance. One of these strains is the multidrug-resistant $E$. coli strain that produces extended-spectrum $\beta$ lactamases (ESBL). The occurrence of extended spectrum beta lactamases-producing E. coli which initiate treatment failure of cephalosporin therapy has become an important epidemiological event (Wu et al., 2019). ESBL gene confers resistance to various antibiotics including penicillin, aztreonam and cephalosporin. In addition, it could also confers resistance to other antibiotic classes that include aminoglycosides, trimethoprimsulfamethoxazole and quinolones (Paterson et al., 2000; Oteo et al., 2001; Paterson and
Bonomo, 2005; Rawat and Nair, 2010; Ghafourian et al., 2014). It is demonstrated that the clinical importance of ESBL-producing $E$. coli isolates is relevant due to limited therapeutic options and high risk of treatment failure in bloodstream infected patients (Hyle et al., 2005; Serefhanoglu et al., 2009). It is therefore, important to determine risk factors for the infection with multidrug-resistant ESBL-producing E.coli isolates in order to improving the therapeutic strategy.

The objective of this study was to determine the prevalence and risk factors associated with ESBL-producing $E$. coli among infants and neonates at the Yaoundé University Hospital Center and Yaoundé Gynecology, Obstetrics and Pediatrics Hospital, two hospitals in city of Yaoundé. The results obtained at the end of this study may contribute to develop an efficient therapeutic strategy for the treatment of community- and hospital-acquired bloodstream ESBLproducing $E$. coli infection by neonatal patients.

\section{MATERIALS AND METHODS}

Sample collection and bacteria
identification

The cross-sectional study was carried out in the pediatric department of the Yaoundé Gynecology, Obstetrics and Pediatrics Hospital (YGOPH) and Yaoundé University hospital center (YUHC) between August and October 2017. Patients between 0 and 42 weeks of age visiting the neonate service for consultation due to sepsis suspicion as well as other infectious diseases of bacterial origin or those hospitalized were included in this study. Before any blood test, parents first filled out a survey sheet containing questionnaires to measure specific parameters. Thereafter, venous blood sample between 1 to $5 \mathrm{~mL}$ were collected and immediately inoculated in a pediatric blood culture bottle containing trypticase soy broth supplemented with growth agents, reducing agents and anticoagulant (Oxoid Limited, Thermo Fisher, Hampshire, England), and incubated at $37{ }^{\circ} \mathrm{C}$. Gram staining test was also performed from positive blood samples and a subculture on Mac 
Conkey agar medium was done for the selection of Enterobacteria. The identification of bacteria strains was done using the galleries API 20E system (BioMérieux SA, Marcy l'étoile, France) as described by the manufacturer instructions.

\section{Antibiotic susceptibility test}

The antibiogram was performed by the diffusion method using antibiotic discs in agar medium on Mueller Hinton agar according to the Kirby Bauer technique (CA-SFM, 2014). Fifteen (15) antibiotics (BioMérieux SA, Marcy l'etoile, France) that include amoxicillin $(30 \mu \mathrm{g})$, amoxicillin + clavulanic acid $(30 \mu \mathrm{g}$; Augmentin), cefotaxime $(30 \mu \mathrm{g})$, ceftazidine $(30 \mu \mathrm{g})$, cefepime $(30 \mu \mathrm{g})$, cefoxitin $(30 \mu \mathrm{g})$, amikacin $(30 \mu \mathrm{g})$, nalidixic acid $(30 \mu \mathrm{g})$, ertapenem $(30 \mu \mathrm{g})$, ciprofoxacin $(30 \mu \mathrm{g})$, ofloxacin $(30 \mu \mathrm{g})$, fosfomycin $(30 \mu \mathrm{g})$, kanamycin $(30 \mu \mathrm{g})$, cotrimoxin $(30 \mu \mathrm{g})$ and gentamycin $(30 \mu \mathrm{g})$ were used. The inoculums were prepared from an 18-24 hour pure colony culture in sterile physiological water $(0.85 \%$ $\mathrm{NaCl}$ ). The suspension was standardized to 0.5 Mac Farland. The results were interpreted according to the criteria of the "Comité d'Antibiogramme de la Société Française de Microbiologie" (CA-SFM, 2014).

\section{Screening of ESBL producing strains of $E$. coli}

The screening test for the production of ESBL was performed using both ceftazidime (CAZ) $(30 \mu \mathrm{g})$ and Ceftriaxone (CTR) $(30 \mu \mathrm{g})$ disks. If the zone of inhibition was less than or equal to $22 \mathrm{~mm}$ for CAZ and/or less than or equal to $25 \mathrm{~mm}$ for CTR, the $E$. coli isolate was considered a potential ESBL-producer as recommended by the Clinical and Laboratory Standard Institute (CLSI, 2014). To confirm the production of ESBL, susceptible E. coli bacteria screened for ESBL production were subjected to combined disk diffusion test using CAZ $(30 \mu \mathrm{g})$, alone and in combination with clavulanic acid (CA) $(10 \mu \mathrm{g})$. After overnight incubation at $37{ }^{\circ} \mathrm{C}$, if the zone of inhibition was higher or equal to $5 \mathrm{~mm}$ for both antibiotic tested and in combination to clavulanate, the $E$. coli strain considered as positive for ESBL production.

\section{Data management and statistical analysis} Data extracted were entered in Microsoft Excel 2010 spreadsheet and the variables presented as percentage. The statistical analysis of all data was done using the IBM Statistical Package for the Social Sciences version 11.0 (SPSS Inc, Chicago, USA). The antibiotic susceptibility and frequency of infections caused by ESBLproducing $E$. coli was reported as the number of infections per 100 positive patients. Univariate and multivariate analysis were performed using logistic regression. Multivariate analysis of characteristic features for bloodstream infection of ESBL-producing $E$ coli included the following variables; three months hospitalization, antibiotic exposure, immune depression and blood transfusion. To assess the risk factors associated with ESBLproducing $E$. coli, the categorical variables were compared using the Fischer test. Odds ratios (OR) and 95\% confidence intervals (95\% CI) were calculated on the Open Epi Info website (www.openepi.com). The multivariate analysis was performed using a conditional logistic regression model (SAS University Edition, SAS Institute Inc., Cary, USA) by including the variables suggested by the univariate analysis $(\mathrm{p}<0.1)$. All tests were bilateral and $p<0.05$ was considered to be statistically significant.

\section{Administrative and ethical consideration}

This study was approved by the Medical Ethical Committee of the "Université des Montagnes" (2017/155/UdM/PR/CAB/CIE). In addition, Permissions to collect data and samples from eligible patients were granted by the Yaoundé University Hospital Center (783/AR/CHUY/DG/DGA/DMT) and Yaoundé Gynecology, Obstetrics and Pediatrics Hospital (580/CIERSH/DM/2017). Prior to entering the study, interested parents received verbal and written information on the objectives and procedure of the study. All eligible parents were provided informed 
consent according to the Declaration of Helsinki on Ethical Principles for Medical Research Involving Human Subjects. In addition, each parent signed the informed consent form for the infants or neonates patients. The confidentiality of the research results was respected by the use of a unique research identity number for each participant.

\section{RESULTS \\ Demographic characteristics and bacterial isolates}

During the study period, 298 patients aged 0 to 42 weeks old were selected among the 660 children present. Patients participating to this study were either attending the hospital for consultation or simply hospitalized because of bacterial infection. More than half $(81.9 \%$; $\mathrm{n}=244$ ) of the patients were between 0 to 4 weeks (neonates) of aged while $61 \%(\mathrm{n}=182)$ were between 0 and 1 week old and $41.9 \%$ $(\mathrm{n}=125)$ were one day old or less. Among these patients, $51 \%(\mathrm{n}=152)$ were male and $49 \%$ $(n=146)$ female and most of them were patients who came to the hospital for consultation. Furthermore, $65 \%$ of the patients were from the pediatric department of YGOPH and 35\% from the Yaoundé University hospital center (YUHC). Blood culture test showed that 129 (43.3\%) samples were positive and indicated the presence of bacterial infection.

\section{Isolation and Identification of bacterial strains}

Screening of the 129 positive blood samples using the antibiotic susceptibility method allowed the isolation of 129 strains among which $69.77 \%$ (n=90) were $E$. coli and $39(30.23 \%)$ bacterial isolates were from other strains which includes Klebsiella oxytoca, Streptococcus pneumoniae and Coagulasenegative staphylococci (Table 1). Of the $90 \mathrm{E}$. coli isolates, $39(43.3 \%)$ were form the blood samples of patients aged one day or less, while $65(72.22 \%)$ were found in the blood samples of newborns patients aged 0 to 4 weeks and 25 $(27.77 \%)$ were from the blood samples of patients aged between 4 to 42 weeks. Further analysis showed that each patient was colonized by one type of micro-organism.

\section{Characterization of the $E$. coli strains}

All E. coli isolates $(\mathrm{n}=90)$ were characterized by the disc diffusion method using 7 antibiotic of the B-lactam family (two penicillin's, four cephalosporin's and one carbapenems). The results are shown in Table 2 and highlight a higher resistance rate $(85.5 \%)$ of $E$. coli to two antibiotics (amoxicillin and augmentin) of the penicillin family. In addition, E. coli exhibited an average resistance to three antibiotics of the cephalosporin family, namely ceftazidime $(65.55 \%)$, cefepime $(58.88 \%)$ and cefoxitin $(55.55 \%)$. Moreover, $67.8 \%(n=61)$ of the isolated E. coli strains were resistant to third generation cephalosporin (ceftazidime and cefotaxime), while $30 \%(\mathrm{n}=27)$ were resistant to second generation cephalosporin (cefoxitin) and $58.88 \%$ (53/90) were resistant to fourth generation cephalosporin (cefepime).In contrast, some E. coli isolates showed a low resistance rate $(30 \%, 24.44 \%)$ when the cephalosporin cefotaxim and the carbapenems, meropenem were used as antibiotic, respectively (Table 2 ).

The susceptibility of $E$. coli isolates to other antibiotic families was also tested (Table 3). In the first instance, the antibiotic susceptibility of E. coli isolates was tested using 3 antibiotic discs belonging to the quinolones family. Results of these tests indicated that the E. coli isolates were weakly resistant to ciprofloxacin (36.66\%), nalidixic acid $(34.44 \%)$ and ofloxacin $(27.77 \%)$, three antibiotics of the quinolones family. In contrast, the antibiotic susceptibility test of the E. coli isolates provided a significantly higher resistance rate when the antibiotic of the sulfonamides family, co-trimoxazole (92.2, $\mathrm{n}=83$ ) was used (Table 3). Likewise, a higher resistance rate in similar test was also observed when an antibiotic of the aminoglycoside family (Amikacin, 54.44\%; Gentamicin, 57.77\%; Kanamycin, 98.88\%) was used (Table 3).

\section{Extended spectrum $\beta$-lactamases (ESBL)- producing phenotypes among $E$. coli isolates}

To further characterize the 90 strains of $E$. coli isolates obtained in this study, the strains that express the ESBL phenotype was identified. Therefore, the double disc approximation test was performed. This 
method allowed to detecting the production of broad-spectrum $\beta$-lactamases by $31 \mathrm{E}$. coli isolates out of a total of 90 , representing a prevalence rate of $34.44 \%$. Moreover, $35.5 \%$ $(11 / 31)$ of $E$. coli isolates expressing the ESBL phenotype were isolated from the blood sample of patients aged one day or less, while 9.7\% $(03 / 31)$ of $E$. coli isolates expressing the ESBL phenotype were isolated from the blood samples of patients aged 1 to 7 days and 32.3\% $(10 / 31)$ of $E$. coli isolates expressing the ESBL phenotype were isolated from the blood samples of patients aged between 1 to 4 weeks. In summary, $83.3 \%(25 / 31)$ of the E. coli isolates expressing the ESBL phenotype were from neonatal patients, which is considered as the period beginning at birth and ending at $28^{\text {th }}$ days (WHO, 2006; Pathirana et al., 2016). Four (4) $(12.9 \%)$ E. coli isolates with ESBL phenotype were found in the blood samples of patients aged 4 to 12 weeks, while the blood samples of patients aged between 3 to 10 months old showed 9.7\% (3/31) frequency of E. coli isolates with ESBL phenotype.

\section{Risk factors associated with ESBL- producing $\boldsymbol{E}$. coli isolates}

Multivariate logistic regression analysis revealed that hospitalization was not a risk factor for infection by ESBL-producing $E$. coli. Multivariate regression analysis indicated that prior exposure to antibiotics was associated with risks of infection by ESBL-producing $E$. coli $(\mathrm{OR}=1.97 ; 95 \% \mathrm{CI}=1.02 ; 3.83 ; p=0.04)$. A more detailed analysis indicated that among the tested antibiotics, only antibiotics of the $\beta$ lactams families was likely to associated the higher risk of infection with ESBL-phenotype by $E$. $\operatorname{coli}(\mathrm{OR}=3.54 ; 95 \% \mathrm{CI}=1.28-9.80 ; p=$ 0.014) (Table 4). Further analysis showed that condition such as immune depression was a significant risk factor associated with the infection by ESBL-producing $E$. coli $(\mathrm{OR}=$ $19.93 ; 95 \% \mathrm{CI}=8.82 ; 45.32 ; p=0.0001)$, while blood transfusion $(\mathrm{OR}=2.48 ; 95 \% \mathrm{CI}=0.95$ $6.45 ; p=0.06$ ) was not (Table 4 ).

Table 1: Microbiological profile of the bacterial isolates.

\begin{tabular}{lcc}
\hline Bacteria isolates & Size (n) & Percentage (\%) \\
\hline Escherichia coli & 90 & 69.77 \\
\hline Other bacteria strains & 39 & 30.23 \\
\hline Klebsiella oxytoca & - & - \\
Streptococcus pneumoniae & - & - \\
Coagulase-negative staphylococci & - & - \\
\hline
\end{tabular}

Table 2: Susceptibility of $E$. coli isolates to antibiotics of $\beta$-lactams family.

\begin{tabular}{llcc}
\hline \multirow{2}{*}{ Antibiotic family } & Antibiotics & \multicolumn{2}{c}{ Resistance } \\
\cline { 3 - 4 } Cephalosporin's & Cefepime & 53 & Percentage (\%) \\
& Ceftazidime & 59 & 58.88 \\
& Cefotaxime & 50 & 65.55 \\
& Cefoxitin & 27 & 55.55 \\
& Amoxicillin & 77 & 30 \\
\hline Penicillin's & Amoxicillin & 77 & 85.55 \\
& clavulanic acid & & 85.55 \\
\hline Carbapenem & Meropenem & 22 & 24.44 \\
\hline
\end{tabular}


Table 3: Susceptibility of $E$. coli isolates to other antibiotics families.

\begin{tabular}{llcc}
\hline \multirow{2}{*}{ Antibiotic family } & Antibiotics & \multicolumn{2}{c}{ Resistance } \\
\cline { 3 - 4 } & & Size (n) & Percentage (\%) \\
\hline Sulfonamides & Cotrimoxazole & 83 & 92.2 \\
\hline Quinolones & Ciprofloxacin & 33 & 36.66 \\
& Nalidixic acid & 31 & 34.44 \\
& Ofloxacin & 25 & 27.77 \\
\hline Aminoglycosides & Amikacin & 49 & 54,44 \\
& Gentamicin & 52 & 57.77 \\
& Kanamycin & 89 & 98.88 \\
\hline
\end{tabular}

Table 4: Multivariate analysis on risk factors for the bloodstream infection by ESBL-producing $E$. coli.

\begin{tabular}{cccc}
\hline Variables & Odds ratio(OR) & $\begin{array}{c}\text { 95\% confidence } \\
\text { interval (CI) }\end{array}$ & p-value \\
\hline $\begin{array}{c}\text { Three months Hospitalization } \\
\text { No }\end{array}$ & 1.0 & & \\
Yes & 2.94 & $0.97 ; 8.91$ & 0.06 \\
\hline $\begin{array}{c}\text { Prior exposure to antibiotics } \\
\text { No }\end{array}$ & 1.0 & & \\
Yes & 1.97 & $1.02 ; 3.83$ & 0,04 \\
\hline B-lactams & & & \\
No & 1.0 & $1.28 ; 9.80$ & 0.01 \\
Yes & 3.54 & & \\
\hline Amino glycosides & 1.0 & & 0.41 \\
No & 1.0 & $1.0 ; 1.33$ & \\
Yes & 19.93 & $8.82 ; 45.32$ & 0.0001 \\
Immune depression & 2.48 & $0.95 ; 6.45$ & 0.06 \\
\hline Blood transfusion & &
\end{tabular}




\section{DISCUSSION}

The management of septicemia and other pathologies caused by bacterial infections in children is based on urgent and adequate presumptive antibiotic therapy. The choice of molecules used requires knowledge of local bacterial ecology and the sensitivity of germs to antibiotics. It is for the specific purpose of improving the management of infectious diseases of bacterial origin that the rate and risk factors of extended spectrum $\beta$-lactamases (ESBLs)-producing E. coli isolated from bloodstream cultures of neonates and an infant at two hospitals in Yaoundé (Cameroon) was estimated. The results of this study revealed that the average combined prevalence of infection with ESBL-producing E. coli among these patients at both hospitals in high. Further analysis showed that risk factors for infection with ESBL-producing E. coli included prior exposure to antibiotics of $\beta$-lactams family and immune depression. The neonatal infection reported here may be caused by mother to child infection during childbirth since it happens early in child life as already reported by other investigation (Kari et al., 2014). The current study may contribute to the improvement therapeutic strategy against EBSL-related diseases in Cameroon and Africa in general.

The overall bacterial profile in this study revealed a predominance of $E$. coli $(69.8 \% ; \mathrm{n}=90)$ as the major bacterial specie and the remaining composed of $30.2 \% \quad(n=39)$ Klebsiella oxytoca, Streptococcus pneumonia and Coagulase negative staphylococci. This finding is similar to that described by Chiabi et al. in Bertoua (2005) and Yaoundé (2011), Cameroon. In addition, similar data have also been reported in countries like Morocco (Chemsi and Benomar, 2015), Tunisia (Ben et al., 2013) and India (Manta et al., 2015). Further investigations using antibody susceptibility test indicated a higher prevalence of E. coli resistance toward amoxicillin/ amoxicillin added to clavulanic acid, two antibiotics of the penicellin's family. In addition, higher $E$ coli resistant rate toward antibiotics third generation cephalosporin was also observed. It is important to mention that increased resistance to third generation cephalosporin (3GC) is a serious concern for community-onset E. coli infection in Africa because this antibiotic is easily accessible to population. In this condition, delay of effective treatment is observed because of misuse of antibiotic, therefore leading to increased morbidity and mortality in the concerned population. Other studies from around the world have already reported similar resistance rates of E. coli to third generation (GbaguidiHaore et al., 2013; Lin et al., 2019; Lester et al, 2020). Likewise, E. coli isolates in this study displayed a resistance to cotrimoxazole and kanamycin, two antibiotics of the sulfonamide and aminoglycoside family, respectively. Together with the resistance observed toward the 3GC antibiotic, this suggests a limited therapeutic strategy to cure bacterial infections that affects the investigated patients at both hospitals. In addition, studies from around the world have reported similar resistance rate (Le Doare et al., 2015; de Oliveira et al., 2019).

Infections initiated by the enzyme ESBL-producing Enterobacteriaceae are resistant to a broad range of $\beta$-lactams, including 3GC. Among all the pathogens, E. coli has emerged as one of the world's greatest health threats in past two decades (Padmini et al., 2017). The high rate of ESBL-producing $E$. coli strains found in this study should be interpreted with caution. But potential reasons may be related to the fact that when infections are suspected for the first time in primary care unit, antibiotics may be prescribed without drawing any biological sample since microbiology laboratories are not well equipped and lack most of the reagents needed to perform a proper diagnostic. Indeed, antibiotic prescriptions prior to blood culture are also reported in pediatric care units of other African countries (Blomberg et al., 2007; Ndir et al., 2016). In addition, other interpretation for the high rate of ESBL-producing $E$. coli observed in this study may also implicate the overuse and misuse of antibiotic drugs prior to hospitalization and antibiotic prescribing errors as also reported elsewhere (Davies and Davies, 2010; Hosoglu et al., 2013; Abera et al., 2014; Shiva et al., 2018). It is also important to mentioning that consumption of food- 
containing antimicrobial substances like pesticides may also be one of reasons for the appearance of antimicrobial resistance in infants and neonates in this study since other publications have reported that pesticides consumption through may initiate antibiotic resistance in bacteria (Bell et al., 2014; Gondam et al., 2016).

In this study, hospitalization and blood transfusion were not significantly associated with increased risk for ESBL-producing $E$. coli infection. In contrast, antibiotic misuse was strongly associated with risk for infection by antibiotic resistant $E$. coli. Although exposure to several antibiotic classes prior to hospitalization or physician consultation were significant on univariate statistical analysis, only exposure to $\beta$-lactams antibiotic family remained statistically significant in the multivariable regression models. In addition, it is demonstrated that children who had exposure to $\beta$-lactams antibiotic family had three to four times greater risk for ESBLassociated infection (Zaoutis et al., 2005; Kuo et al., 2007; Topaloglu et al., 2010; Kizilca et al., 2012; Flokas et al., 2016; Li et al., 2018; Hu et al., 2019). The high rates of $\beta$-lactams resistance observed here complicate the management of the disease initiated by infection with ESBL-producing $E$. coli, therefore lead to the use of other antibiotic family and thus considerably increasing the cost of treatment. Similar findings are reported by other investigators (Tenover et al., 1999; Kim et al., 2002; Zaoutis et al., 2005; Ndir et al., 2016). Another risk factors for bloodstream infection observed in this study was immune depression which was significant associated with high risk infection with ESBL-producing E. coli in children.

\section{Conclusion}

It was noticed that out of 129 bacteria isolated from newborm bloodstream, 90 were E. coli. In addition, a large number of the isolated $E$. coli strains showed a significantly high resistance to cepholosporins, penicillins, sulfonamides and aminoglycosides. Furthermore, the high rate of ESBL-producing E. coli obtained in this study is an emergent cause of neonatal death locally recorded. It was also found that previous exposure antibodies and more specifically to antibiotics of the $\beta$ lactams family and a preexisting immune depression condition were risk factors associated to the infection to ESBL-producing E. coli. From these findings, there is reason to be concerned about the installation of the ESBL plasmids encoding this species in neonatal population in both healthcare institutions. This work should make it possible to adapt the probabilistic antibiotic therapy of bacteremia, and to set up a strategy to control the development and spread of multi-resistant bacteria. Reinforced hygiene measures in hospitals and communities could reduce bacteremia with multi-resistant germs.

\section{COMPETING INTERESTS} interests.

The authors declare no competing

\section{AUTHORS' CONTRIBUTIONS}

SNF conceived and designed the study. Patient recruitment and data collection were done by CSLT. SNF, HKG and CSLT conducted the data analysis. SNF, HKG and CSLT interpreted study results. SNF wrote the manuscript. All authors approved the final copy.

\section{ACKNOWLEDGMENTS}

We are grateful to all who participated in this research, especially the nurses of the YGOPH and YUHC pediatric departments who helped in patient's recruitment and blood samples collection. The authors would like to thank Dr Majeste Pahane for critical reading.

\section{REFERENCES}

Abera B, Kibret M, Mulu W. 2014. Knowledge and beliefs on antimicrobial resistance among physicians and nurses in hospitals in Amhara Region, Ethiopia. $B M C$ Pharmacol. Toxicol., 15: 26. DOI: https://doi.org/10.1186/2050-6511-15-26

Bell BG, Schellevis F, Stobberingh E, Goossens H, Pringle M. 2014. A systematic review and meta-analysis of the effects of antibiotic consumption on 
antibiotic resistance. BMC Infect. Dis., 14: $13 . \quad$ DOI: https://doi.org/10.1186/1471-2334-14-13

Ben N, Bouziri A, Kchaou W, Hamdi A, Mnif K, Belhadji F, Khaldi A, Kazdaghli K. 2013. Epidemiologie des infections bacteriennes nosocomiale dans une unité de réanomation néonatale et pédiatrique Tunisienne. Med. Mal. Infect., 36(7): 37985.

DOI: https://doi.org/10.1016/j.medmal.2006.0 5.004

Blomberg B, Manji KP, Urassa WK, Tamim BS, Mwakagile DSM, Jureen R, Msangi V, Tellevik MG, Holberg-Petersen M, Harthug S, Maselle SY, Langeland N. 2007. Antimicrobial resistance predicts death in Tanzanian children with bloodstream infections: a prospective cohort study. BMC Infect. Dis., 7: 43. DOI: https://doi.org/10.1186/1471-2334$7-43$

CA-SFM. 2014. Recommandations. Comité d'Antibiogramme de la Société Française de Microbiologie.

Chemsi M, Benomar S. 2015. Infection bactérienne néonatale précoce. J. Pédiatr. Puéricult., 28(1): 2937. DOI: 10.1016/j.jpp.2014.10.005

Chiabi A, Fokam P, Aly T, Nguele M, Sihom P, Tetang M, Yan YX. 2005. Les infections néonatales bactériennes en milieu rural au Cameroun. Clin. Mother Child Health., 2(1): 22934.

Chiabi A, Djoupomb M, Mah E, Nguefack S, Mbuagbaw L, Zafack J, Ghoyap M, Nkoa T, Tchokoteu PF. 2011. The Clinical and Bacteriogical Spectrum of Neonatal Sepsis inaTertiary Hospital in Yaounde, Cameroon. Iran J. Pediat., 21(4): 441448.

CLSI. 2014. Performance standards for antimicrobial susceptibility testing; Twenty-fourth informational supplement. M100 S24. Clinical and Laboratory Standards Institute, Wayne (PA).

Daga AP, Koga VL, Soncini JGM, de Matos CM, Perugini MRE, Pelisson M, Kobayashi RKT, Vespero EC. 2019. Escherichia coli Bloodstream Infections in Patients at a University Hospital: Virulence Factors and Clinical Characteristics. Front. Cell Infect. Microbiol., 9: 191. DOI: https://doi.org/10.3389/fcimb.2019.0019 1

Davies J, Davies D. 2010. Origins and evolution of antibiotic resistance. Microbiol Mol Biol Rev., 74(3):417-33. DOI: https://doi.org/10.1128/MMBR.0001610

de Oliveira PMN, Buonora SN, Souza CLP, Simões Júnior R, da Silva TC, Bom GJT, da Silva Teixeira $\mathrm{CH}$, da Silva ARA. 2019. Surveillance of multidrug-resistant bacteria in pediatric and neonatal intensive care units in Rio de Janeiro State, Brazil. JBSTM., 52:e20190205. DOI: https://doi.org/10.1590/0037-86820205-2019

Flokas ME, Detsis M, Alevizakos M, Mylonakis E. 2016. Prevalence of ESBLproducing Enterobacteriaceae in paediatric urinary tract infections:A systematic review and meta-analysis. $J$ Infect., $\quad \mathbf{7 3}(6)$ :547-57. DOI: https://doi.org/10.1016/j.jinf.2016.07.01 4

Gbaguidi-Haore H, Dumartin C, L'Heriteau F, Pefau M, Hocquet D, Rogues AM, Bertrand X, the ATB-RAISIN network steering committee. 2013. Antibiotics involved in the occurrence of antibioticresistant bacteria: a nationwide multilevel study suggests differences within antibiotic classes. J. Antimicrob. Chemothe., 68: 461-470. DOI: https://doi.org/10.1093/jac/dks406

Ghafourian S, Sadeghifard N, Soheili S, Sekawi Z. 2014. Extended Spectrum Beta-lactamases: Definition, Classification and Epidemiology. Curr. Issues Mol. Biol., 17: 11-22. DOI: http://dx.doi.org/10.21775/cimb.017.011

Gondam KM, Tatfo KF, Yangoua MH, Kansci G, Medoua NG. 2016. Antimicrobial usage in the chicken farming in Yaoundé, Cameroon: a cross-sectional study. Food Contamination, $\quad 3$ : $10 . \quad$ DOI: 
https://doi.org/10.1186/s40550-0160034-6

Hosoglu S, Parlak Z, Geyik MF, Palanci Y. 2013. Critical evaluation of antimicrobial use-a Turkish university hospital example. J. Infect. Dev. Ctries., 7(11): 873-879.

DOI: https://doi.org/10.3855/jidc.2921

Hu YJ, Ogyu A, Cowling BJ, Fukuda K, Pang HH. 2019. Available evidence of antibiotic resistance from extendedspectrum B-lactamase-producing Enterobacteriaceae in paediatric patients in 20 countries: a systematic review and meta-analysis. Bull. World Health Organ., 97: 486-501. DOI: https://doi.org/10.2471/BLT.18.225698

Hyle EP, Lipworth AD, Zaoutis TE, Nachamkin I, Fishman NO, Bilker WB, Mao X, Lautenbach E. 2005. Risk Factors for Increasing Multidrug Resistance among Extended-Spectrum BLactamaseProducing Escherichia coli and Klebsiella Species. Clin. Infect. Dis., 40: 1317-1324. DOI: http://dx.doi.org/10.1086/429239

Kari A, Ann L, Shirley F, Dele H. 2014. Early onset neonatal sepsis. Clin. Microbiol. Rev., 27(1): $2147 . \quad$ DOI: http://dx.doi.org/10.1128/CMR.0003113

Kim YK, Pai H, Lee HJ, Choi EH, Kim J, Kim JH, Kim EC. 2002. Bloodstream infections by extendedspectrum betalactamase-producing Escherichia coli and Klebsiella pneumoniae in children: epidemiology and clinical outcome. Antimicrob. Agents Chemother., 46: 1481-1491. DOI: https://doi.org/10.1128/aac.46.5.14811491.2002

Kizilca O, Siraneci R, Yilmaz A, Hatipoglu N, Ozturk E, Kiyak A, Ozkok D. 2012. Risk factors for community-acquired urinary tract infection caused by ESBLproducing bacteria in children. Pediatr. Int., 54(6): 858-862.

DOI: https://doi.org/10.1111/j.1442200X.2012.03709.x
Kuo KC, Shen YH, Hwang KP. 2007. Clinical implications and risk factors of extendedspectrum beta-lactamase-producing Klebsiella pneumonia infection in children: a case-control retrospective study in a medical center in southern Taiwan. J. Microbiol. Immunol. Infect., 40(3): 248-254.

Le Doare K, Bielick J, Heath P, Sharland M. 2015. Systematic Review of Antibiotic Resistance Rates Among Gram-Negative Bacteria in Children With Sepsis in Resource-Limited Countries. J. Pediatric Infect. Dis. Soc., 4(1): 11-20. DOI: https://doi.org/10.1093/jpids/piu014

Leimbach A, Hacker J, Dobrindt UE. 2013. Coli as an All-Rounder: The Thin Line Between Commensalism and Pathogenicity. Curr. Top. Microbiol. Immunol., 358: 3-32. DOI: https://doi.org/ 10.1007/82_2012_303

Lester R, Musicha $\mathrm{P}$, van Ginneken N, Dramowski A, Hamer DH, Garner P, Feasey NA. 2020. Prevalence and outcome of bloodstream infections due to third-generation cephalosporin-resistant Enterobacteriaceae in sub-Saharan Africa: a systematic review. $J$. Antimicrob. Chemother., 75(3): 492-507. DOI: https://doi.org/10.1093/jac/dkz464

Li D, Sick-Samuels AC, Suwantarat N, Same RG, Simner PJ, Tamma PD. 2018. Risk factors for extended-spectrum betalactamase-producing Enterobacteriaceae carriage upon pediatric intensive care unit admission. Infect. Control Hosp. Epidemiol., 39(1): 116-118. DOI: https://doi.org/10.1017/ice.2017.246

Lin W, Huang Y, Wang J, Chen Y, Chang S. 2019. Prevalence of and risk factor for community-onset third-generation cephalosporin-resistant Escherichia coli bacteremia at a medical center in Taiwan. BMC Infect. Dis., 19: 245. DOI: https://doi.org/10.1186/s12879-0193880-z

Manta J, Kapil K, Garg L, Vikas M, Mittal S. 2015. To study the incidence and risk factors of early onset neonatal sepsis in an out born neonatal intensive unit care of 
Indian. J. Clin. Neonatal., 11: 154-72. DOI: $\quad$ https://doi.org/10.4103/22494847.154106

Ndir A, Diop A, Faye PM, Cissé MF, Ndoye B, Astagneau P. 2016. Epidemiology and Burden of Bloodstream Infections Caused by Extended Spectrum Beta-Lactamase Producing Enterobacteriaceae in a Pediatric Hospital in Senegal. PLoS ONE., 11(2): e0143729. DOI: https://doi.org/10.1371/journal.pone.014 3729

Oteo J, Campos J, Baquero F. 2001. Antibiotic resistance in 1962 invasive isolates of Escherichia coli in 27 Spanish hospitals participating in the European Antimicrobial Resistance Surveillance System. J. Antimicrob. Chemother., 50: 945-952.

DOI: https://doi.org/10.1093/jac/dkf255

Padmini N, Ajilda AAK, Sivakumar N, Selvakumar G. 2017. Extended spectrum $\beta$-lactamase producingEscherichia coliandKlebsiella pneumoniae: critical tools for antibiotic resistance pattern. $J$. Basic Microbiol., 57(6): 460-470. DOI: https://doi.org/10.1002/jobm.201700008

Paneth N, Thompson T. 2018. Neonatal and Perinatal Epidemiology. Avery's Diseases of the Newborn (Tenth Edition), p1-10.e2.

DOI: https://doi.org/10.1016/B978-0-32340139-5.00065-6

Paterson DL, Mulazimoglu L, Casellas JM, Ko WC, Goossens H, Von Gottberg A, Mohapatra S, Trenholme GM, Klugman KP, McCormack JG, Yu VL. 2000. Epidemiology of ciprofloxacin resistance and its relationship to extended-spectrum beta-lactamase production in Klebsiella pneumoniae isolates causing bacteremia. Clin. Infect. Dis., 30: 473-478. DOI: https://doi.org/ 10.1086/313719.

Paterson DL, Bonomo RA. 2005. Extendedspectrum beta-lactamases: a clinical update. Clin. Microbiol. Rev., 18: 657686.

DOI:

https://doi.org/10.1128/CMR.18.4.657686.2005
Pathirana J, Muñoz FM, Abbing-Karahagopian V, Bhat N, Harris T, Kapoor A, Keene DL, Mangili A, Padula MA, Pande SL, Pool V, Pourmalek F, Varricchio F, Kochhar S, Cutland CL. 2016. Neonatal death: Case definition \& guidelines for data collection, analysis, and presentation of immunization safety data. Vaccine, 34(49): 6027-6037. DOI: http://dx.doi.org/10.1016/j.vaccine.2016. 03.040

Rawat D, Nair D. 2010. Extended-spectrum Blactamases in Gram Negative Bacteria. $J$. Glob. Infect. Dis., 2: 263-274. DOI: https://doi.org/10.4103/0974777X.68531

Remington JS, Klein JO. 1995. Infectious Diseases of the Fetus and Newborn Infant $\left(7^{\text {th }}\right.$ edn). W.B. Saunders Company: Philadelphia.

Roser M, Ritchie H, Dadonaite B. 2020. "Child and Infant Mortality". Published online at OurWorldInData.org. Retrieved from: 'https://ourworldindata.org/childmortality'

Serefhanoglu K, Turan H, Timurkaynak FE, Arslan H. 2009. Bloodstream Infections Caused by ESBL-Producing E. coli and $K$. pneumoniae: Risk Factors for Multidrug-Resistance. BJID., 13: 403407. DOI: http://dx.doi.org/10.1590/s141386702009000600003

Shiva F, Ghanaie R, Shirvani F, Armin S, Rafiei Tabatabaei S, Alireza Fahimzad S, Fallah F, PourMoshtagh H, Karimi A. 2018. Pattern of Antibiotic Usage in Children Hospitalized for Common Infectious Diseases. Arch. Pediatr. Infect. Dis., $\quad$ 6(1): e34474. DOI: https://doi.org/10.5812/pedinfect.34474

Tam IP-Y, Bendel CM. 2017. Diagnostics for neonatal sepsis: current approaches and future directions. Pediatric Res., 82(4): 574-584. DOI: 10.1038/pr.2017.134

48. Tenover FC, Mohammed MJ, Gorton TS, Dembek ZF. 1999. Detection and reporting of organisms producing extended-spectrum beta-lactamases: survey of laboratories in Connecticut. $J$ 
Clin Microbiol., 37: 4065-4070. DOI: https://doi.org/10.1128/JCM.37.12.40654070.1999

THE WHO YOUNG INFANTS STUDY GROUP. 1999. Clinical prediction of serious bacterial infections in young infants in developing countries: results of a multicenter study. Pediatr. Infect. Dis. J., 18(10): S23-31. DOI: 10.1097/00006454-199910001-00005

Topaloglu R, Er I, Dogan BG, Bilginer Y, Ozaltin F, Besbas N, Ozen S, Bakkaloglu A, Gur D. 2010. Risk factors in community-acquired urinary tract infections caused by ESBL-producing bacteria in children. Pediatr Nephrol., 25(5): 919-925.

DOI: https://doi.org/10.1007/s00467-0091431-3

World Health Organization. 2006. Neonatal and perinatal mortality: country, regional and global estimates. WHO Libr.

World Health organization. 2019. Newborns: reducing mortality, WHO. https://www.who.int/news-room/factsheets/detail/children-reducing-mortality. Wu P-C, Wang J-L, Hsueh P-R, Lin P-H, Cheng M-F, Huang I-F, Chen Y-S, ShinJung Lee S, Guang-Yuan M, Yu H-C, Hsu C-L, Wang F-W, Chen C-S, Hung CH, KoW-C. 2019. Prevalence and risk factors for colonization by extendedspectrum $\beta$-lactamase-producing or ST 131 Escherichia coli among asymptomatic adults in community settings in Southern Taiwan. Infect. Drug. Resist., 12: 1063-1071. DOI: https://doi.org/ 10.2147/IDR.S201086

Zaoutis TE, Goyal M, Chu JH, Coffin SE, Bell LM, Nachamkin I, Mc Gowan KL, Bilker WB, Lautenbach E. 2005. Risk factors for and outcomes of bloodstream infection caused by extendedspectrum $\beta$ lactamase-producing Escherichia coli and Klebsiella species in children. Pediatrics., 115(4): 942-949. DOI: https://doi.org/10.1542/peds.2004-1289. 